\section{Genetic dissection of the miR-17 92 cluster of microRNAs in Myc-induced B-cell lymphomas}

\author{
Ping Mu, ${ }^{1,5}$ Yoon-Chi Han,, ${ }^{1,5}$ Doron Betel, ${ }^{2}$ \\ Evelyn Yao, ${ }^{1}$ Massimo Squatrito, ${ }^{1}$ \\ Paul Ogrodowski, ${ }^{1}$ Elisa de Stanchina, ${ }^{3}$ \\ Aleco D'Andrea, ${ }^{1,4}$ Chris Sander, ${ }^{2}$ \\ and Andrea Ventura ${ }^{1,6}$
}

${ }^{1}$ Cancer Biology and Genetics Program, Memorial Sloan
Kettering Cancer Center, New York, New York 10021, USA;
${ }^{2}$ Computational Biology Center, Memorial Sloan Kettering
Cancer Center, New York, New York 10021, USA; ${ }^{3}$ Department
of Molecular Pharmacology and Chemistry, Memorial Sloan
Kettering Cancer Center, New York, New York 10021, USA;
${ }^{4}$ Department of Surgical and Oncological Sciences, Section of
Medical Oncology, Università di Palermo, Palermo 90133, Italy

The miR-17 92 cluster is frequently amplified or overexpressed in human cancers and has emerged as the prototypical oncogenic polycistron microRNA (miRNA). miR-17 92 is a direct transcriptional target of c-Myc, and experiments in a mouse model of B-cell lymphomas have shown cooperation between these two oncogenes. However, both the molecular mechanism underlying this cooperation and the individual miRNAs that are responsible for it are unknown. By using a conditional knockout allele of miR-17 92, we show here that sustained expression of endogenous miR-17 92 is required to suppress apoptosis in Myc-driven B-cell lymphomas. Furthermore, we show that among the six miRNAs that are encoded by miR-17 92, miR-19a and miR-19b are absolutely required and largely sufficient to recapitulate the oncogenic properties of the entire cluster. Finally, by combining computational target prediction, gene expression profiling, and an in vitro screening strategy, we identify a subset of miR-19 targets that mediate its prosurvival activity.

Supplemental material is available at http://www.genesdev.org.

Received October 11, 2009; revised version accepted

November 3, 2009.

The miR-17 92 cluster encodes six distinct microRNAs (miRNAs) that are processed from a common primary transcript (Fig. 1A; for review, see Mendell 2008). A growing body of evidence points to an important role of this cluster of miRNAs in the pathogenesis of human cancers (for review, see Ventura and Jacks 2009). Over-

[Keywords: microRNAs; Myc; $m i R-17 \sim 92$; cancer; mouse]

${ }^{5}$ These authors contributed equally to this work.

${ }^{6}$ Corresponding author.

E-MAIL venturaa@mskcc.org; FAX (646) 422-0871.

Article is online at http://www.genesdev.org/cgi/doi/10.1101/gad.1872909. expression of $m i R-17 \sim 92$ is observed in a large fraction of human cancers, including carcinomas of the breast, lung, and colon; medulloblastomas; neuroblastomas; and B-cell lymphomas (Hayashita et al. 2005; He et al. 2005; Tagawa and Seto 2005; Fontana et al. 2008; Uziel et al. 2009). In addition, a substantial fraction of diffuse large B-cell lymphomas harbors recurrent genomic amplification of the miR-17 92 locus (Ota et al. 2004).

The evidence for a causal link between miR-17 92 overexpression and tumorigenesis is strengthened by the observation that transgenic expression of this cluster in mice leads to a lymphoproliferative disorder (Xiao et al. 2008), while its genetic ablation impairs normal B-cell development (Ventura et al. 2008). In addition, ectopic expression of miR-17 92 cooperates with the c-Myc oncogene in a mouse model of B-cell lymphomas (He et al. 2005). The functional interplay between miR17 92 and c-Myc is further underlined by the finding that c-Myc itself is a potent and direct transcriptional activator of miR-17 92 (O'Donnell et al. 2005), thus suggesting that miR-17 92 may contribute to the oncogenic properties of c-Myc.

The experiments presented in this study were designed to examine the role of the endogenous miR-17 92 allele in Myc-driven lymphomas, and to determine the relative contribution of each of the six constituent miRNAs to the overall oncogenic potential of the cluster.

Our results show that, in the context of Myc-driven B-cell lymphomas, genetic ablation of the endogenous miR-17 92 locus leads to a dramatic reduction of tumor cell growth in vitro and suppresses tumorigenicity in vivo, two effects that are largely the consequence of increased cell death. We also demonstrate that, among the six miRNAs encoded by the miR-17 92 cluster, the members of the miR-19 family $(m i R-19 a$ and miR-19b) are essential to mediate the oncogenic activity of the entire cluster, and that they do so at least in part by modulating the expression of the tumor suppressor gene Pten (phosphatase and tensin homologous).

\section{Results and Discussion}

Generation of miR-17 92 flox/flox $; E \mu-M y c$ mice

To investigate the role of miR-17 92 in Myc-induced cancers, we employed the $E \mu-M y c$ mouse model of B-cell lymphomas (Adams et al. 1985). E $\mu-M y c$ mice express a $c-M y c$ transgene under the control of the B-cell-specific E $\mu$ enhancer and develop B-cell lymphomas within 4-6 mo of age (Adams et al. 1985). E $\mu$-Myc mice were crossed to mice carrying a conditional miR-17 92 knockout allele $\left(\right.$ miR-17 92 $\left.^{\mathrm{fl}}\right)$ (Fig. 1B; Ventura et al. 2008). To temporally control the deletion of the floxed miR-17 92 allele, these mice were further crossed to mice carrying a 4-hydroxytamoxifen (4-OHT)-inducible Cre-recombinase estrogen receptor-T2 $\left(C r e-E R^{T 2}\right)$ knock-in allele targeted to the ubiquitously expressed ROSA26 locus (R26-Cre-ER ${ }^{T 2}$ mice, hereafter referred to as Cre-ER) (Ventura et al. 2007).

As expected, $E \mu-M y c ; m i R-17 \sim 92^{f l / f l}$; Cre-ER mice developed B-cell lymphomas with similar latency and phenotype as the parental $E \mu-M y c$ strain (data not shown). From these mice, we derived two independent lymphoma lines (AV4174 and AV4182) that could be 


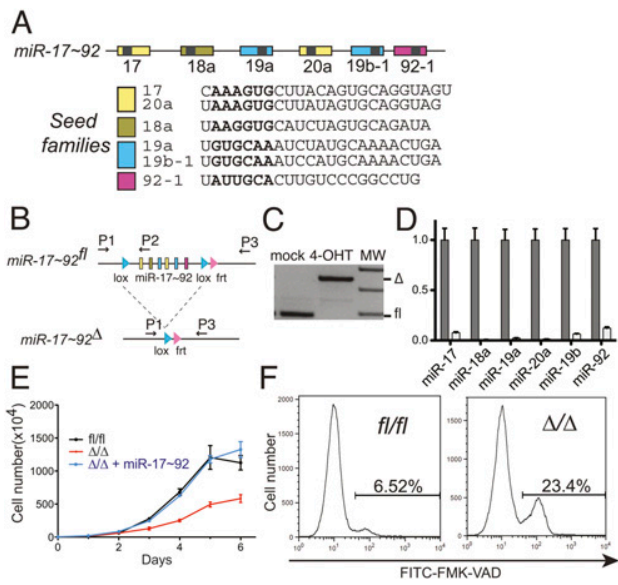

Figure 1. miR-17 92 suppresses cell death in $E \mu-M y c$ lymphomas. (A) Schematic representation of the miR-17 92 cluster. Each miRNA is represented by a colored box and is color-coded based on the seed family to which it belongs. The sequence of each mature miRNA is also shown. $(B)$ Schematic of the conditional miR-17 92 knockout allele. Arrows represent the primers used to detect the floxed and the deleted $(\Delta)$ alleles. $(C)$ PCR on genomic DNA extracted from $E \mu-M y c ; m i R-17 \sim 92^{f l / f l}$;Cre-ER lymphoma cells mocktreated or after $4 \mathrm{~d}$ of 4-OHT treatment. $(D)$ Quantitative RT-PCR analysis of the expression of miR-17 92 in lymphoma cells before (gray bars) and after (white bars) 4-OHT treatment. Each component of miR-17 92 was detected independently, and the results were normalized relative to the expression observed in mock-treated cells. Each experiment was performed in quadruplicate. Error bar, standard deviation (SD). (E) Growth curves of miR-17 $\sim 92^{\mathrm{fl} / \mathrm{fl}}$ cells (black line), $m i R-17 \sim 92^{\Delta / \Delta}$ cells (red line), and miR-17 92 $4 / \Delta$ cells infected with a retrovirus expressing the entire miR-17 92 cluster (blue line). Error bars, SD of three replicates. The plot is representative of three independent experiments. $(F)$ Caspase activity

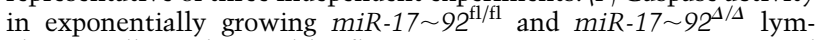
phoma cells as detected by flow cytometry using FITC-conjugated VAD-FMK. The percent of VAD-FMK ${ }^{+}$cells is shown.

propagated easily in culture and readily formed tumors when injected into immunocompromised mice. Both lymphoma lines exhibited similar behavior in vitro and in vivo. Unless otherwise specified, the experiments discussed here were performed using the AV4182 cell line.

To determine the efficiency of $m i R-17 \sim 92$ deletion, miR-17 92 $2^{\mathrm{fl} / \mathrm{fl}}$ lymphoma cells were treated with $250 \mathrm{nM}$ 4-OHT. This treatment lead to the efficient deletion of both endogenous $\mathrm{miR}-17 \sim 92$ alleles (Fig. 1C), with concomitant loss of expression of the corresponding miRNAs (Fig. 1D).

We next examined the phenotypic consequences of deleting miR-17 92 in B-lymphoma cells. Because sustained Cre expression has been reported to negatively affect the growth of $E \mu-M y c$ lymphoma cells (SchmidtSupprian and Rajewsky 2007), 4-OHT was administered for $4 \mathrm{~d}$, after which the lymphoma cells were allowed to recover for a minimum of $4 \mathrm{~d}$ before being examined. As shown in Figure 1E, deletion of miR-17 92 dramatically reduced the proliferation of $E \mu-M y c$ lymphoma cells. Importantly, this phenotype was fully rescued by reintroduction of the entire miR-17 92 cluster (Fig. 1E).

The different growth kinetics between the miR17 $\sim 92^{f 1 / f 1}$ and $m i R-17 \sim 92^{\Delta / \Delta}$ lymphoma cells could be due to the latter displaying reduced proliferation, increased spontaneous cell death, or a combination of both.
While cell cycle distribution and BrdU incorporation were similar between $m i R-17 \sim 92^{\mathrm{fl} / \mathrm{fl}}$ and $m i R-17 \sim 92^{\Delta / \Delta}$ cells (Supplemental Fig. 1A), the fraction of cells undergoing apoptosis, as determined by detecting caspase activation, was approximately fourfold higher in the absence of $\operatorname{miR}-17 \sim 92$ (Fig. 1F). Increased apoptosis was confirmed by measuring the DNA fragmentation using the TUNEL assay (Supplemental Fig. 1B). These results demonstrate that expression of the endogenous $m i R$ 17 92 locus is required for the optimal survival of Mycdriven B-lymphoma cells. In addition, they are consistent with the finding by $\mathrm{He}$ et al. (2005) that ectopic expression of $m i R-17 \sim 92$ cooperates with $\mathrm{c}-\mathrm{Myc}$ by reducing spontaneous apoptosis.

\section{miR-19a and miR-19b mediate the oncogenic} properties of $m i R-17 \sim 92$

This observation provides a rationale and an opportunity to genetically dissect the functions of this cluster and to identify its relevant target mRNAs. The six miRNAs encoded by miR-17 92 can be grouped into four "seed families," based on sequence identity at positions 2-7 (Fig. 1A): the miR-17 family (miR-17 and $m i R-20 a)$, the miR-18 family $(m i R-18 a)$, the miR-19 family $(m i R-19 a$ and miR-19b-1), and the miR-92 family (miR-92-1). miRNAs belonging to the same seed family are predicted to target highly overlapping sets of mRNAs, and thus are expected to exert similar biological functions (Bartel 2009). To examine the role of each seed family in the context of $E \mu-M y c$ lymphomas, we generated a series of $m i R-17 \sim 92$ mutant alleles, each lacking expression of the miRNA(s) belonging to one of the four seed families (Supplemental Fig. 2A). The wild-type and the mutant alleles of $m i R$ 17 92 were cloned into MSCV-Puro-IRES-GFP (PIG), a retroviral vector encoding the green fluorescent protein (GFP) and the Puromycin resistance gene, and the resulting constructs were transduced into $\mathrm{miR}-17 \sim 92^{\Delta / \Delta} \mathrm{lym}$ phoma cells. First, we verified that these constructs correctly expressed the desired miRNAs (Supplemental Fig. 2B). This was an essential control because deletion of even a single miRNA from the miR-17 92 cluster could, in principle, negatively affect the processing and expression of the remaining ones, thus compromising our experimental approach.

To determine the ability of each construct to rescue the phenotype caused by $m i R-17 \sim 92$ deletion, we titrated the viral preparations to achieve an infection efficiency of $5 \%-30 \%$, as judged by GFP expression. We reasoned that, if reintroduction of $m i R-17 \sim 92$ or one of its derivatives is sufficient to suppress the increased cell death observed in miR-17 92 $2^{\Delta / \Delta}$ cells, it will provide the infected cells with a growth advantage that will in turn be reflected by an increase in the fraction of GFP-positive cells over time (see schematic in Fig. 2A). As predicted, reintroduction of the full-length $m i R-17 \sim 92$ cluster resulted in a rapid increase of $\mathrm{GFP}^{+}$cells that quickly outcompeted the uninfected cells (Fig. 2B). Interestingly, among the four mutant constructs, only the one lacking the miR-19 seed family $(\Delta 19 \mathrm{a}, 19 \mathrm{~b})$ failed to provide a growth advantage (Fig. 2B,C) and to suppress the increased apoptosis caused by deletion of $m i R-17 \sim 92$ (Fig. $2 \mathrm{D}$ ), suggesting that this seed family is necessary for the oncogenic properties of the cluster. This was further confirmed by showing that reintroduction of $m i R-19 a$ and $m i R-19 b$ alone was largely sufficient to rescue the growth defect caused by deletion 

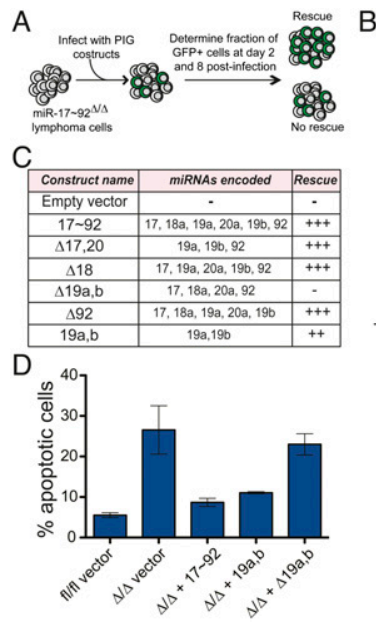

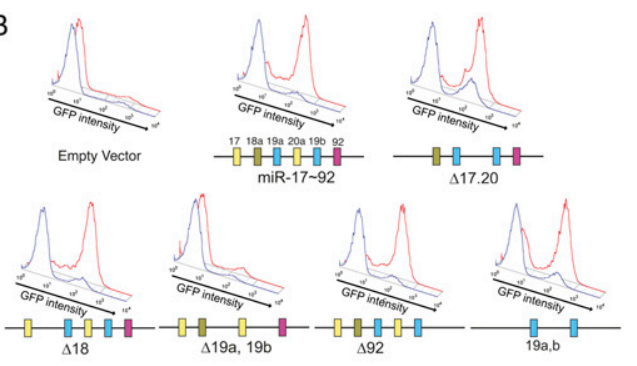

E

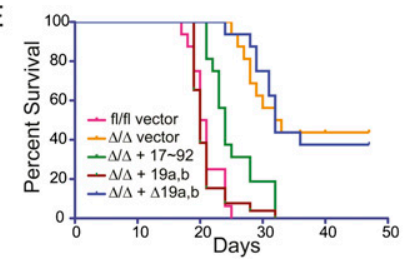

Figure 2. $m i R-19 a$ and $m i R-19 b$ mediate the prosurvival and oncogenic functions of miR-17 92 in E $\mu$-Myc B-cell lymphomas. $(A)$ Schematic of the experimental design. (B) Histogram overlays of miR-17 92 ${ }^{\Delta / \Delta}$ cells transduced with PIG retroviruses expressing the indicated $m i R-17 \sim 92$ derivatives. The cells were assayed by flow cytometry to detect GFP expression at day 2 (blue plot) and day 8 (red plot) post-infection. A schematic of the miR-17 92 derivative used is shown below each overlay. $(C)$ Table summarizing the results of the experiments shown in $B$. (D) Caspase activity in $m i R-17 \sim 92^{\mathrm{fl} / \mathrm{fl}}$ and $m i R-17 \sim 92^{\Delta / \Delta}$ cells transduced with the indicated PIG constructs. Error bar, 1 SD deviation. $(E)$ Survival analysis of mice injected with $m i R-17 \sim 92^{\mathrm{fl} / \mathrm{fl}}$ and $\mathrm{miR}-17 \sim 92^{\Delta / \Delta}$ lymphoma cells transduced with the indicated PIG constructs. $N=16$ mice for each construct, over three independent experiments.

of the entire $m i R-17 \sim 92$ cluster and to suppress apoptosis (Fig. 2B,D, miR-19a,b construct).

\section{Deletion of miR-19 affects tumorigenicity in vivo}

To determine whether the miR-19 seed family is required for the tumorigenicity of $E \mu$-Myc-driven B-cell lymphomas in vivo, we injected a cohort of nude mice with $m i R$ $17 \sim 92^{f l / f l}$ and $m i R-17 \sim 92^{\Delta / \Delta}$ lymphoma cells. While miR-17 92 fl/f1 cells invariably lead to the formation of lymphomas that lead to death within 2-3 wk, the miR$17 \sim 92^{\Delta / \Delta}$ cells produced lymphomas with a significantly $(P<0.0001)$ longer latency (Fig. 2E). Tumorigenicity was fully restored by ectopic expression of the full-length miR-17 92 cluster $(P<0.0001)$, but not by expression of the $m i R-17 \sim 92$ mutant lacking $m i R-19 a$ and $m i R-19 b$ $(P=0.9816)$ (Fig. 2E). Re-expression of $m i R-19 a$ and $m i R-$ $19 \mathrm{~b}$ also largely rescued tumorigenicity, although it did so somewhat less efficiently than the full-length $\mathrm{miR}$ 17 92 $(P=0.0002$ for the comparison between $\Delta / \Delta$ and $\Delta / \Delta+$ miR-19a, b; $P=0.0013$ for the comparison between $\mathrm{fl} / \mathrm{fl}$ and $\Delta / \Delta+\mathrm{miR}-19 \mathrm{a}, \mathrm{b})$.

\section{Identification of miR-19 targets in B-cell lymphomas}

Having demonstrated a critical role of $m i R-19 a$ and $m i R-$ $19 b$ in Myc-driven B-cell lymphomas, we next sought to identify their functionally relevant target mRNAs. miRNA target prediction algorithms (TargetScan, Miranda, and Pictar) (John et al. 2004; Krek et al. 2005; Grimson et al. 2007; Betel et al. 2008) identify several hundreds of potential targets of miR-19; however, only a fraction of these mRNAs will likely be functionally relevant in any particular cellular context. To identify the genes whose expression is effectively modulated by $\mathrm{miR}$ -

17 92 in B-cell lymphomas, we compared the gene expression profile of the AV4182 cell line before and after deletion of $\mathrm{miR}-17 \sim 92 / \mathrm{fl} / \mathrm{fl}$ vs. $\Delta / \Delta)$. We also included $m i R-17 \sim 92^{\Delta / \Delta}$ lymphoma cells that had been transduced with either PIG-miR-17 92 ${ }^{\text {wt }}$ or PIG-miR-19a/19b (Fig. 3A). In choosing this approach, we were supported by a number of recent reports showing that mRNA destabilization contributes to miRNA-mediated regulation of gene expression (Bagga et al. 2005; Lim et al. 2005; Baek et al. 2008; Selbach et al. 2008), which can be detected by conventional mRNA expression arrays. As predicted, deletion of $m i R-17 \sim 92$ led to the preferential up-regulation of genes whose $3^{\prime}$ untranslated regions (UTRs) contain seed matches for the miRNAs encoded by this cluster $(P$-value $<2.22 \mathrm{e}-16$, KS test) (Fig. 3B; Supplemental Fig. 3). Accordingly, ectopic expression of $m i R-17 \sim 92$ in $m i R-17 \sim 92^{\Delta / \Delta}$ cells led to the preferential down-regulation of $m i R$ 17 92 targets $(P$-value $<2.22 \mathrm{e}-16, \mathrm{KS}$ test $)$ (Fig. 3C; Supplemental Fig. 3). Finally, reintroduction of a mutant version of the miR-17 92 cluster expressing only $\operatorname{miR}-19 a$ and $m i R-19 b$ selectively affected mRNAs carrying binding sites for these two miRNAs $(P$-value $=6.35 \mathrm{e}-15)$, but not genes with binding sites for the other members of the $m i R-17 \sim 92$ cluster.

By comparing the four gene expression profiles, we identified a total of 568 genes whose expression was up-regulated $(\log 2$ expression change $>0.20)$ by deletion of the endogenous $m i R-17 \sim 29$ locus (fl/fl vs. $\Delta / \Delta$ comparison) and down-regulated by the reintroduction of the full-length $m i R-17 \sim 92$ cluster $(m i R-17 \sim 92$ vs. $\Delta / \Delta)$ and of $m i R-19 a$ and $m i R-19 b$ only $(m i R-19 a / b$ vs. $\Delta / \Delta ; \log 2$ expression change $<-0.20)$ (Fig. 3D). Ninetyfive of them contained in their $3^{\prime} \mathrm{UTR}$ one or more conserved binding sites for miR-19, according to TargetScan 5.1 (Fig. 3E; Supplemental Table 1), and were analyzed further. Guided by our findings that miR-19 suppresses apoptosis in $E \mu$-Myc lymphoma cells, we inspected the list of 95 genes and selected a subset of 46 of them for functional validation (Fig. 4A; Supplemental Table 2). We reasoned that, if $m i R-19$ promotes survival by repressing the expression of one or more of these genes, this effect should be at least partially phenocopied by RNAi-mediated knockdown of the relevant targets. To test this hypothesis, for each of the 46 genes selected for validation we designed three shRNAs. The shRNAs were cloned into the MLP vector, a retroviral vector also expressing GFP, and each construct was individually transduced into miR-17 92 $2^{\Delta / \Delta}$ lymphoma cells. Analogous to the experiments described in Figure 2A, the viral preparations were titrated in order to achieve a transduction efficiency of $5 \%-30 \%$, and the fraction of $\mathrm{GFP}^{+}$cells was measured $2 \mathrm{~d}$ after infection (day 0) and again $11 \mathrm{~d}$ later. The results of this experiment are summarized in Figure 4B. For the majority of shRNAs, the fraction of $\mathrm{GFP}^{+}$-positive cells did not change over time or, for a small number of them, was lower at day 11 compared with day 0 , indicating that expression of the shRNA did not provide any growth advantage to the infected cells or was detrimental, respectively (Fig. 4B; Supplemental Table 2). However, for a subset of shRNAs, we observed a significant increase in 
A
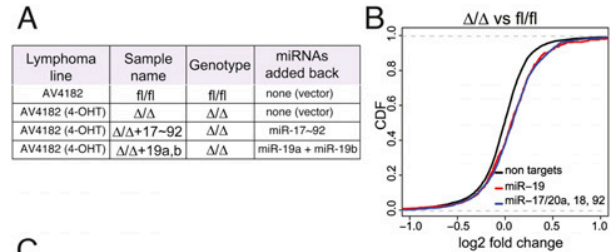

C

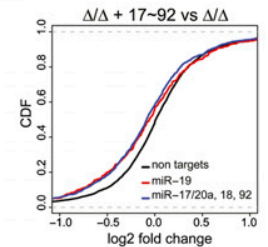

$\mathrm{D}_{\Delta \Delta+}$
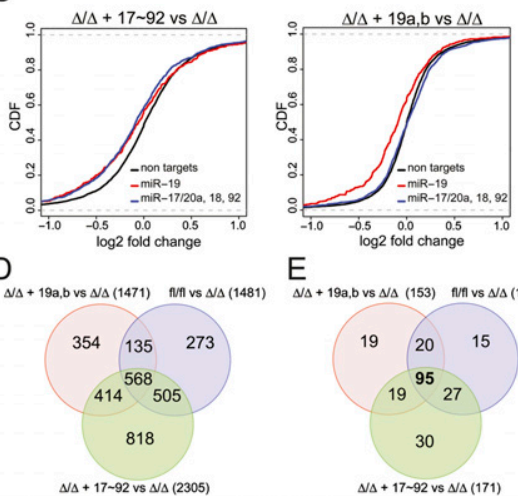

E

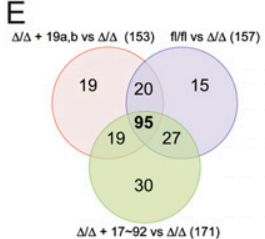

Figure 3. Gene expression profiling identifies miR-19 targets in $E \mu$ Myc lymphoma cells. (A) Description of the various lymphoma cells used. $(B)$ Differences in mRNA levels between $m i R-17 \sim 92^{\mathrm{fl} / \mathrm{fl}}$ and miR-17 $92^{\Delta / \Delta}$ lymphoma cells transduced with the empty PIG vector were monitored with microarrays. Cumulative distribution function (CDF) plots are shown for mRNAs that do not contain miR17 92 seed matches in their 3'UTRs (black line), mRNAs containing one or more seed matches for miR-19 in their 3'UTR (red line), and mRNAs containing one or more seed matches for either miR-17, miR-20a, miR-18a, or miR-92 (blue line). In the absence of endogenous $m i R-17 \sim 92$ expression, a statistically significant up-regulation $(P$-value $<2.22 \mathrm{e}-16$, KS test $)$ is observed for the predicted miR17 92 targets relative to the background gene population. (C) CDF plots of the changes in mRNA expression levels between miR-

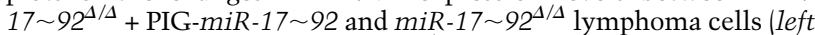

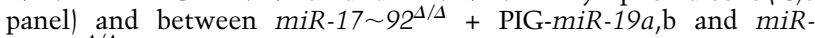
$17 \sim 92^{\Delta / \Delta}$ lymphoma cells (right panel). (D) Venn diagram summarizing the overlap in gene expression changes observed between the various transduction experiments. $(E)$ As in $D$, but the analysis was restricted to mRNAs whose 3'UTR contains at least one predicted binding site for miR-19.

the fraction of $\mathrm{GFP}^{+}$cells at day 11 compared with day 0 (Fig. 4B; Supplemental Fig. 5). Among them, two out of three shRNAs targeting the Pten tumor suppressor gene had the largest effect, largely phenocopying ectopic expression of $m i R-19 a / b$. A third shRNA directed against the Pten mRNA had a more modest, but still significant, effect. In addition, a number of the other shRNAs provided a significant growth advantage, although the effect was more modest than that observed with Pten shRNAs (Fig. 4B; Supplemental Table 2). In particular, all three shRNAs directed against $S b f 2$ and two out of three directed against $B c 17 a$ and $R n f 44$ scored positive in this screening, suggesting that these three genes may contribute to the prosurvival functions of miR-19.

PTEN is one of the most frequently mutated tumor suppressor genes in human cancers, and monoallelic mutations at this locus are observed in $>50 \%$ of sporadic tumors (for review, see Salmena et al. 2008). In mice, homozygous deletion of Pten leads to early embryonic lethality, while heterozygotes show greatly increased incidence of a variety of tumors, including T-cell lymphomas, as well as tumors of endometrium, liver, prostate, gastrointestinal tract, and thyroid (Di Cristofano et al. 1998; Suzuki et al. 1998; Podsypanina et al. 1999). Functionally, PTEN is a phospholipid phosphatase that acts as a negative regulator of cell survival and protein synthesis via inhibition of the AKT/mammalian target of rapamycin (mTOR) pathway. Studies in mouse models and mutational analysis of human tumors indicate that Pten is an haploinsufficient tumor suppressor gene (Salmena et al. 2008), suggesting that even modest modulation of its levels by miRNAs may have functional consequences.

The Pten 3'UTR contains two conserved binding sites for $m i R-19 a$ and $m i R-19 b$ (Fig. 5A), and it has been shown previously to be a direct miR-19 target $\left(\mathrm{O}^{\prime}\right.$ Donnell et al. 2005; Xiao et al. 2008). We first confirmed that miR-19 directly acts on the Pten 3'UTR via binding to the two predicted sites by performing reporter assays in human cancer cells and in $\mathrm{miR}-17 \sim 92^{+/+}$and $\mathrm{miR}-17 \sim 92^{\Delta / \Delta}$ mouse embryo fibroblasts (Supplemental Fig. 4). We next determined the extent to which Pten expression is modulated by miR-19 in Myc-driven B-cell lymphomas. Western blotting and immunohistochemistry analysis of $m i R-17 \sim 92^{f l / f 1}$ and $m i R-17 \sim 92^{\Delta / \Delta}$ lymphomas confirmed a consistent up-regulation of Pten expression in the latter (Fig. 5B,C). Reintroduction of full-length $m i R-17 \sim 92$ or of miR-19 $a$ and $m i R-19 b$ alone, but not of $m i R-17 \sim 92^{\Delta 19 a, b}$, in $\mathrm{miR}-17 \sim 92^{\Delta / \Delta}$ lymphomas was sufficient to restore Pten expression to levels similar to those observed in miR-17 92 fl/f1 cells (Fig. 5B,C). In addition, analogous to reintroduction of $m i R-19$, RNAi-mediated knockdown of Pten in miR-17 92 $2^{\Delta / \Delta}$ lymphoma cells was sufficient to reduce spontaneous apoptosis to the levels observed in miR-17 92 $2^{\mathrm{fl} / \mathrm{fl}}$ cells (Fig. 5D). We next examined whether Pten knockdown was also sufficient to restore the tumorigenicity of $m i R-17 \sim 92^{\Delta / \Delta}$ lymphoma cells. Mice injected with $\operatorname{miR}-17 \sim 92^{\Delta / \Delta}$; sh-Pten developed aggressive lymphomas that led to death with a latency similar to that observed in mice injected with $m i R-17 \sim 92^{\Delta / \Delta}$ cells ectopically expressing $\mathrm{miR}-19 a / b$ (Fig. 5D). Also in

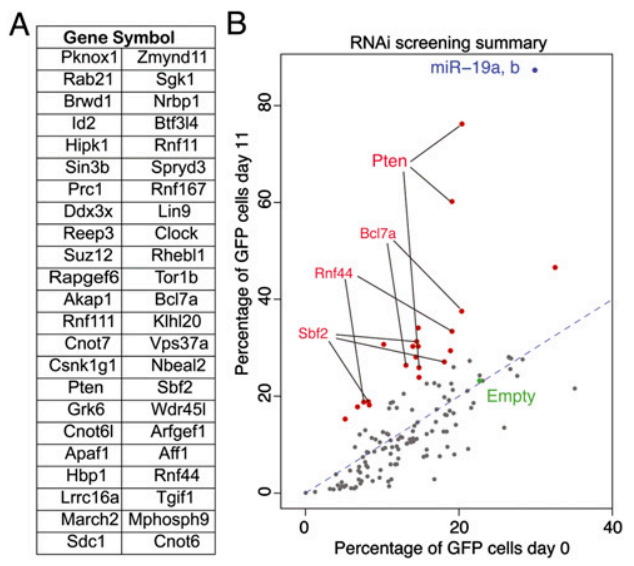

Figure 4. An in vitro RNAi screen to identify functionally relevant miR-19 targets. (A) List of the genes assayed in the in vitro shRNA screen. (B) Scatter plot summarizing the result of the screen. Each dot represents an individual shRNA construct. The $X$-axis is the percentage of GFP cells at the beginning of the experiment $(2 \mathrm{~d}$ after infection) and the $Y$-axis is the percentage of GFP cells $11 \mathrm{~d}$ later. The green dot identifies the empty vector control. shRNAs that scored positive in the screen are highlighted in red and labeled. Dots corresponding to genes for which at least two out of three shRNAs provided significant growth advantage are labeled. PIG-miR-19a/b was included in the screen as positive control (blue dot). 
Mu et al.
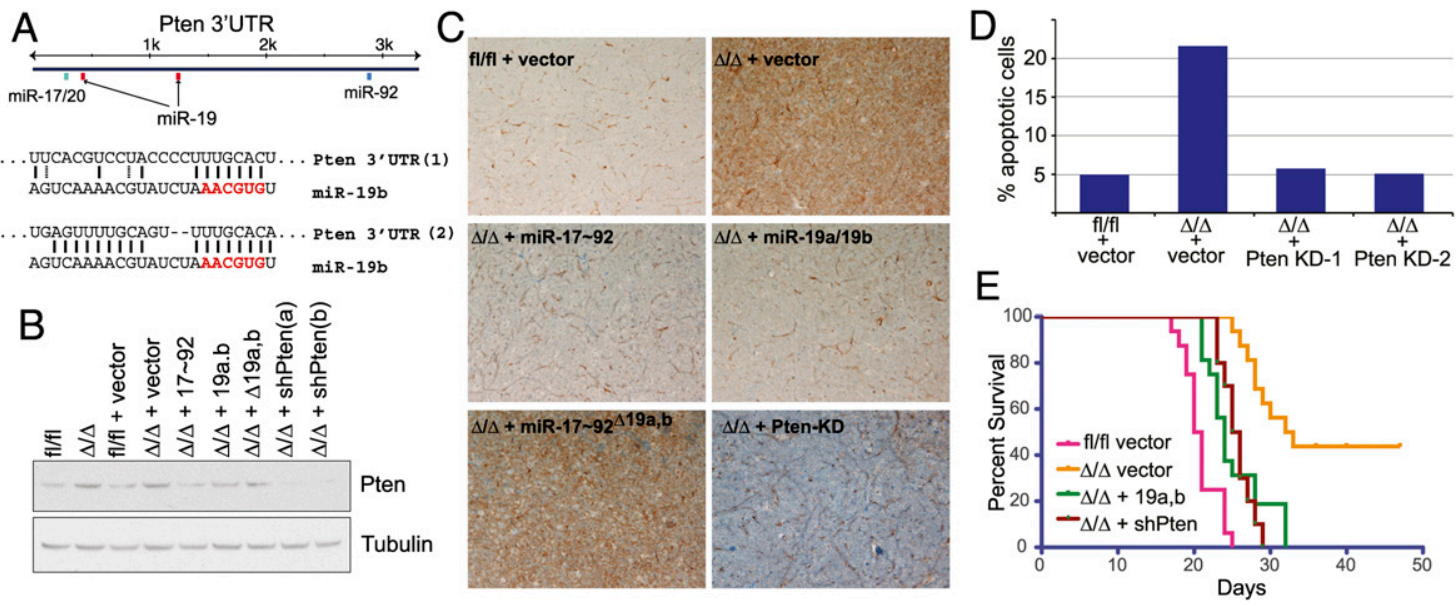

Figure 5. Pten is a functionally relevant miR-19 target in B-cell lymphomas. (A) Schematic representation of the Pten $3^{\prime} U T R$ with the location of the predicted binding sites for members of the miR-17 92 cluster and sequence alignments between miR-19b and its two predicted binding sites. (B) Pten Western blot on lysates of B-lymphoma cells transduced with the indicated PIG constructs. (Lanes 8,9$)$ For comparison, lysates from miR-17 $\sim 92^{\Delta / \Delta}$ cell expressing the two Pten shRNAs that scored positive in the in vitro screen were also assayed. $(C)$ Pten

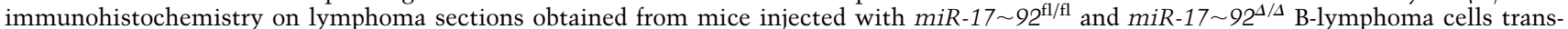
duced with the indicated miR-17 92 derivatives (objective, $20 \times$ ). Brown staining indicates Pten signal. $(D)$ Knockdown of Pten suppresses

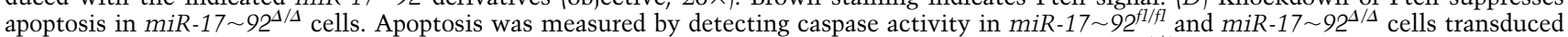
with the indicated retroviruses. (E) Kaplan-Meier survival curve of mice injected with miR-17 92 ${ }^{\Delta / \Delta}$ lymphoma cells transduced with retroviruses expressing shRNAs against Pten. $N=10$ (five mice for shPTEN-1 and five mice for shPTEN-2). For comparison, the survival curves of mice injected with miR-17 92 $2^{\mathrm{fl} / \mathrm{fl}}, \operatorname{miR}-17 \sim 92^{\Delta / \Delta}$, and $m i R-17 \sim 92^{\Delta / \Delta}+$ miR-19a,b from Figure $2 \mathrm{C}$ are included.

this case, survival was slightly longer compared with mice injected with $\mathrm{miR}-17 \sim 92^{\mathrm{fl} / \mathrm{fl}}$ cells $(P=0.0002)$, indicating the existence of additional functionally relevant targets.

In summary, the results presented here provide a mechanistic explanation for the functional cooperation between c-Myc and miR-17 92, identify the miR-19 seed family as the primary oncogenic determinant of this cluster, and pave the way for the development of novel anti-cancer strategies based on the pharmacological inhibition of miR-19 function.

\section{Material and methods}

\section{Mouse husbandry}

Animal studies and procedures were approved by the Memorial Sloan Kettering Cancer Center Institutional Animal Care and Use Committee. Mice were maintained in a mixed 129SvJae and C57/B6 background. The Rosa26-Cre-ER $R^{T 2}$ and $m i R-17 \sim 92^{\mathrm{fl} / \mathrm{fl}}$ mice have been described previously (Ventura et al. 2007, 2008). The $E \mu-M y c$ mice were generated and described by Adams et al. (1985).

For the in vivo tumorigenicity studies, 4- to 8-wk-old athymic (nu/nu) mice were injected intravenously with $10^{5}$ lymphoma cells and monitored daily. Mice were euthanized when moribund. Kaplan-Meier curves were plotted using PRISM software, and the log-rank Mantel-Cox test was used to determine statistical significance.

\section{Antibodies and immunohistochemistry}

Antibodies and experimental conditions for Western blotting and immunohistochemistry are described in the Supplemental Material.

\section{Cell culture and retroviral transduction}

The $E \mu-M y c ; m i R-17 \sim 92^{f 1 / 11} ; C r e-E R^{T 2}$ lymphoma lines were cultured on a feeder of irradiated NIH-3T3 cells in a medium composed of $50 \%$ DMEM and 50\% IMDM, supplemented with $10 \%$ fetal bovine serum.

To induce deletion of the miR-17 92 cluster, cells were incubated for 4 d with $250 \mathrm{nM}$ 4-OHT. During our initial set of experiments with
4-OHT-treated lymphoma cells, we noticed that, upon prolonged passages, the few cells that had escaped full miR-17 92 deletion $\left(m i R-17 \sim 92^{f 1 / f 1}\right.$

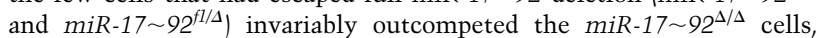
eventually becoming the majority within a couple of weeks. To avoid this limitation and allow the execution of long-term in vivo experiments, $4 \mathrm{~d}$ after 4-OHT treatment, subclones were isolated by plating 10 cells per well into a 96-well plate using a MoFlo fluorescence-activated cell sorter. After expansion, clones composed solely of fully recombined cells were isolated and used for further manipulation.

Retroviruses were generated in Phoenix packaging cells. When required, transduced cells were selected by adding puromycin $(2 \mu \mathrm{g} / \mathrm{mL})$ to the culture medium for $4 \mathrm{~d}$.

\section{Plasmids and shRNA library}

A 1.2-kb fragment encompassing the entire miR-17 92 cluster was PCRamplified from mouse genomic DNA and cloned into the MSCV-PIG retroviral vector (a gift from Mike Hemann, Massachusetts Institute of Technology|. Deletion mutants were by site-directed PCR and verified by sequencing. Primers and sequences are available on request.

The shRNA library was cloned in the MLP retroviral vector (a gift from Michael Hemann, Massachusetts Institute of Technology). For each gene, three shRNA directed against the coding sequence were designed using the RNAi Central resource created by the laboratory of Greg Hannon (http://katahdin.cshl.org:9331/siRNA/RNAi.cgi? type=shRNA). Each construct was sequence-verified.

\section{Apoptosis assays}

Apoptosis was measured using the Caspase Detection Kit (Red-VAD-FMK or FITC-VAD-FMK, Calbiochem) and confirmed using the TUNEL assay (In Situ Cell Death Detection Kit, TMR red, Roche) following the manufacturer's instructions.

\section{Gene expression analysis}

Total RNA extracted from three technical replicates was hybridized to the Affymetrix 430 A2.0 gene chip, following the manufacturer's instruction. Gene expression was normalized using the GCRMA Bioconductor package, and log expression values were computed using the limma package. For genes with multiple probes, the probe with lowest adjusted $P$-value 
was selected. Genes with a log expression change of $<-0.2$ in all three comparisons and with an adjusted $P$-value $<0.05$ in at least one comparison were considered for subsequent overlap analysis.

\section{miRNA target predictions}

miRNA targets were predicted using miRanda (http://www.microrna. org) and TargetScan (http://www.targetscan.org). For the cumulative distribution function $(\mathrm{CDF})$ plots, target sites were restricted to perfect seed complementarity between positions 2 and 7 of the miRNA. Empirical cumulative distributions were computed using $\mathrm{R}$ ecdf function for the set of predicted gene of the transduced miRNAs and for the genes with no target sites (background). $P$-values were computed using the KS twosample test.

\section{Acknowledgments}

We thank Jane Qiu for technical assistance. A.V. is grateful to Tyler Jacks and Robert Benezra for their generosity and support. This work was funded by the Sidney Kimmel Cancer Research Foundation and the Geoffrey Beene Cancer Research Foundation.

\section{References}

Adams JM, Harris AW, Pinkert CA, Corcoran LM, Alexander WS, Cory S, Palmiter RD, Brinster RL. 1985. The c-myc oncogene driven by immunoglobulin enhancers induces lymphoid malignancy in transgenic mice. Nature 318: 533-538.

Baek D, Villén J, Shin C, Camargo FD, Gygi SP, Bartel DP. 2008. The impact of microRNAs on protein output. Nature 455: 64-71.

Bagga S, Bracht J, Hunter S, Massirer K, Holtz J, Eachus R, Pasquinelli AE. 2005. Regulation by let-7 and lin-4 miRNAs results in target mRNA degradation. Cell 122: 553-563.

Bartel DP. 2009. MicroRNAs: Target recognition and regulatory functions. Cell 136: 215-233.

Betel D, Wilson M, Gabow A, Marks DS, Sander C. 2008. The microRNA. org resource: Targets and expression. Nucleic Acids Res 36: D149-D153. doi: 10.1093/nar/gkm995.

Di Cristofano A, Pesce B, Cordon-Cardo C, Pandolfi PP. 1998. Pten is essential for embryonic development and tumour suppression. Nat Genet 19: 348-355.

Fontana L, Fiori ME, Albini S, Cifaldi L, Giovinazzi S, Forloni M, Boldrini R, Donfrancesco A, Federici V, Giacomini P, et al. 2008. Antagomir$17-5 \mathrm{p}$ abolishes the growth of therapy-resistant neuroblastoma through p21 and BIM. PLoS One 3: e2236. doi: 1371/journal.pone. 0002236.

Grimson A, Farh KK, Johnston WK, Garrett-Engele P, Lim LP, Bartel DP. 2007. MicroRNA targeting specificity in mammals: Determinants beyond seed pairing. Mol Cell 27: 91-105.

Hayashita Y, Osada H, Tatematsu Y, Yamada H, Yanagisawa K, Tomida S, Yatabe Y, Kawahara K, Sekido Y, Takahashi T. 2005. A polycistronic microRNA cluster, miR-17-92, is overexpressed in human lung cancers and enhances cell proliferation. Cancer Res 65: 9628-9632.

He L, Thomson JM, Hemann MT, Hernando-Monge E, Mu D, Goodson S, Powers S, Cordon-Cardo C, Lowe SW, Hannon GJ, et al. 2005. A microRNA polycistron as a potential human oncogene. Nature 435: 828-833.

John B, Enright AJ, Aravin A, Tuschl T, Sander C, Marks DS. 2004. Human microRNA targets. PLoS Biol 2: e363. doi: 10.1371/journal. pbio.0020363.

Krek A, Grun D, Poy MN, Wolf R, Rosenberg L, Epstein EJ, MacMenamin P, da Piedade I, Gunsalus KC, Stoffel M, et al. 2005. Combinatorial microRNA target predictions. Nat Genet 37: 495-500.

Lim LP, Lau N, Garrett-Engele P, Grimson A, Schelter J, Castle J, Bartel DP, Linsley PS, Johnson J. 2005. Microarray analysis shows that some microRNAs downregulate large numbers of target mRNAs. Nature 433: 769-773.

Mendell JT. 2008. miRiad roles for the miR-17-92 cluster in development and disease. Cell 133: 217-222.

O'Donnell KA, Wentzel EA, Zeller KI, Dang CV, Mendell JT. 2005. c-Mycregulated microRNAs modulate E2F1 expression. Nature 435: 839843.
Ota A, Tagawa H, Karnan S, Tsuzuki S, Karpas A, Kira S, Yoshida Y, Seto M. 2004. Identification and characterization of a novel gene, C13orf25, as a target for 13q31-q32 amplification in malignant lymphoma. Cancer Res 64: 3087-3095.

Podsypanina K, Ellenson LH, Nemes A, Gu J, Tamura M, Yamada KM, Cordon-Cardo C, Catoretti G, Fisher PE, Parsons R. 1999. Mutation of Pten/Mmacl in mice causes neoplasia in multiple organ systems. Proc Nat1 Acad Sci 96: 1563-1568.

Salmena L, Carracedo A, Pandolfi PP. 2008. Tenets of PTEN tumor suppression. Cell 133: 403-414.

Schmidt-Supprian M, Rajewsky K. 2007. Vagaries of conditional gene targeting. Nat Immunol 8: 665-668.

Selbach M, Schwanhausser B, Thierfelder N, Fang Z, Khanin R, Rajewsky N. 2008. Widespread changes in protein synthesis induced by microRNAs. Nature 455: 58-63.

Suzuki A, de la Pompa JL, Stambolic V, Elia AJ, Sasaki T, del Barco Barrantes I, Ho A, Wakeham A, Itie A, Khoo W, et al. 1998. High cancer susceptibility and embryonic lethality associated with mutation of the PTEN tumor suppressor gene in mice. Curr Biol 8: 11691178 .

Tagawa H, Seto M. 2005. A microRNA cluster as a target of genomic amplification in malignant lymphoma. Leukemia 19: 2013-2016.

Uziel T, Karginov FV, Xie S, Parker JS, Wang YD, Gajjar A, He L, Ellison D, Gilbertson RJ, Hannon G, et al. 2009. The miR-17 92 cluster collaborates with the Sonic Hedgehog pathway in medulloblastoma. Proc Natl Acad Sci 106: 2812-2817.

Ventura A, Jacks T. 2009. MicroRNAs and cancer: Short RNAs go a long way. Cell 136: 586-591.

Ventura A, Kirsch DG, McLaughlin ME, Tuveson DA, Grimm J, Lintault L, Newman J, Reczek EE, Weissleder R, Jacks T. 2007. Restoration of p53 function leads to tumour regression in vivo. Nature 445: 661-665.

Ventura A, Young AG, Winslow MM, Lintault L, Meissner A, Erkeland SI, Newman J, Bronson RT, Crowley D, Stone JR, et al. 2008. Targeted deletion reveals essential and overlapping functions of the miR-17 through 92 family of miRNA clusters. Cell 132: 875-886.

Xiao C, Srinivasan L, Calado DP, Patterson HC, Zhang B, Wang J, Henderson JM, Kutok JL, Rajewsky K. 2008. Lymphoproliferative disease and autoimmunity in mice with increased miR-17-92 expression in lymphocytes. Nat Immunol 9: 405-414. 


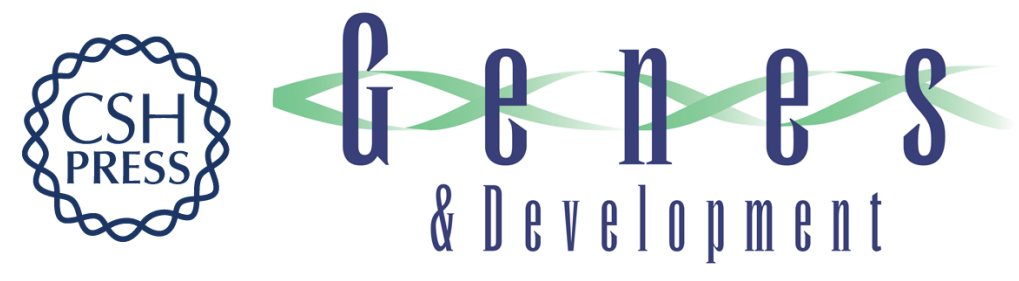

\section{Genetic dissection of the miR-17 92 cluster of microRNAs in Myc-induced B-cell lymphomas}

Ping Mu, Yoon-Chi Han, Doron Betel, et al.

Genes Dev. 2009, 23:

Access the most recent version at doi:10.1101/gad.1872909

\section{Supplemental http://genesdev.cshlp.org/content/suppl/2009/11/30/23.24.2806.DC1 \\ Material}

Related Content Tumorigenicity of the miR-17-92 cluster distilled

Gijs van Haaften and Reuven Agami

Genes Dev. January , $201024: 1-4$ miR-19 is a key oncogenic component of mir-17-92

Virginie Olive, Margaux J. Bennett, James C. Walker, et al.

Genes Dev. December , 2009 23: 2839-2849

References This article cites 27 articles, 4 of which can be accessed free at:

http://genesdev.cshlp.org/content/23/24/2806.full.html\#ref-list-1

Articles cited in:

http://genesdev.cshlp.org/content/23/24/2806.full.html\#related-urls

\section{License}

Email Alerting

Service

Receive free email alerts when new articles cite this article - sign up in the box at the top right corner of the article or click here.

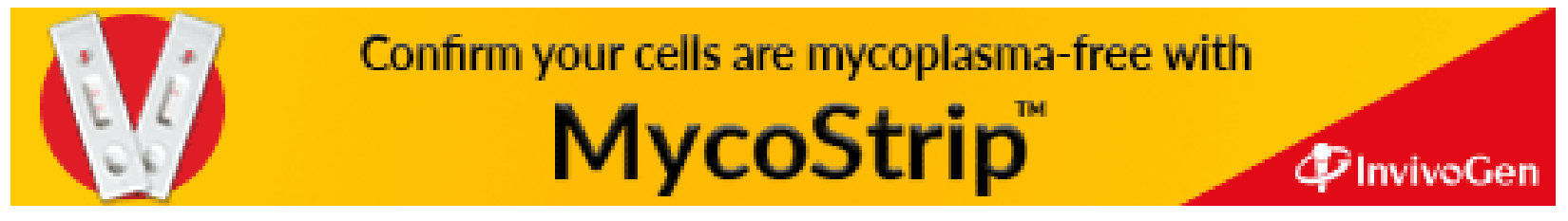

